\title{
Correction to: Changes in forest soil organic matter quality affected by windstorm and wildfire
}

\author{
Gabriela Barančíková ${ }^{1}$ - Maria Jerzykiewicz ${ }^{2}$ - Erika Gömöryová ${ }^{3} \cdot$ Erika Tobiašová $^{4} \cdot$ Tadeáš Litavec $^{1}$
}

Published online: 18 April 2018

(C) Springer-Verlag GmbH Germany, part of Springer Nature 2018

\section{Correction to: J Soils Sediments}

https://doi.org/10.1007/s11368-018-1942-2

In the online and published version of this article there was an error in the name of the corresponding author:

Maria Jarzykiewicz

should be

Maria Jerzykiewicz

The online version of the original article can be found at https://doi.org/ $10.1007 / \mathrm{s} 11368-018-1942-2$

\footnotetext{
Maria Jerzykiewicz

maria.jerzykiewicz@chem.uni.wroc.pl

1 National Agricultural and Food Centre-Soil Science and Conservation Research Institute, Regional Working Place Prešov, 08001 Prešov, Slovakia

2 Faculty of Chemistry, University of Wroclaw, F. Joliot-Curie 14 50-383, Wroclaw, Poland

3 Faculty of Forestry, Technical University in Zvolen, T.G. Masaryka 24, 96053 Zvolen, Slovakia

4 Faculty of Soil Science, Slovak University of Agriculture, Tr. A. Hlinku, 94976 Nitra, Slovakia
} 